\title{
Vegetable intake frequency is higher among the rural than among the urban or suburban residents, and is partially related to vegetable cultivation, receiving, and purchasing at farmers' markets: A cross-sectional study in a city within Gunma, Japan
}

\author{
Daisuke Machida ${ }^{1,2}$, and Tohru Yoshida ${ }^{2}$ \\ ${ }^{1}$ Department of Health and Nutrition, Takasaki University of Health and Welfare, Japan \\ ${ }^{2}$ Gunma University Graduate School of Health Sciences, Japan
}

\begin{abstract}
Objectives: This study aimed at identifying the differences in the vegetable intake frequency among rural, suburban, and urban residents. It also intended to estimate the effects of vegetable cultivation, receiving vegetables, and purchasing vegetables at farmers' markets on the differences in vegetable intake frequency. Based on the results, to promote vegetable intake, we discuss the value of supporting vegetable cultivation in the rural areas.

Materials and Methods: We conducted a cross-sectional study targeting residents aged between 20 and 74, living in three parts of a city within the Gunma prefecture in Japan. The three locations were selected to represent the rural, suburban, and urban areas. We mailed two sets of anonymous self-administered questionnaires to all households in the three areas (a total of 2,260 households, comprising about 1,000 people aged between 20 and 74 in each area). The survey requested information on the vegetable intake frequency, vegetable cultivation, frequency of receiving vegetables, frequency of vegetable purchase at farmers' markets, the subjective difficulty in food-store access, economic circumstances, health attitudes, and demographic characteristics. We used the analysis of covariance (ANCOVA) to examine the data obtained.

Results: We received 873 responses (from 586 households), of which 90 were irrelevant, thus leaving a sample of 783 residents
\end{abstract}

Received: January 11, 2018

Accepted: May 31, 2018

Correspondence: Daisuke Machida, M.S., Takasaki University of Health and Welfare, 37-1 Nakaoorui, Takasaki, Gunma 370-0033, Japan

E-mail: machiad-d@takasaki-u.ac.jp

This is an open-access article distributed under the terms of the Creative Commons Attribution Non-Commercial No Derivatives (by-nc-nd) License $<$ http://creativecommons.org/licenses/by-nc-nd/4.0/>.
(257 rural, 259 suburban, 267 urban) available for statistical analysis. The results revealed that the rural residents had significantly greater vegetable intake frequency than the urban and suburban residents did. These regional differences became smaller after the adjustment of the following variables: vegetable cultivation, receiving vegetables, and vegetable purchase at farmers' markets. No significant difference was observed in the vegetable intake frequency between the rural and urban respondents after this adjustment was made.

Conclusions: Vegetable intake frequency was higher in the rural area than in the suburban and urban areas. Vegetable cultivation, receiving vegetables, and vegetable purchase at farmers' markets were strongly linked to these regional differences.

Key words: vegetable cultivation, vegetable intake frequency, locally grown vegetables, farmers' market, food access

(J Rural Med 2018; 13(2): 116-123)

\section{Introduction}

Consumption of fruits and vegetables is associated with a reduced risk of certain chronic diseases and lower overall mortality. One systematic review indicated the positive effects of fruit and vegetable intake in the prevention of cardiovascular diseases, cancer in general, hypertension, obesity, and obesity-related type- 2 diabetes ${ }^{1}$. Another systematic review revealed a negative relationship between all-cause mortality and fruit and vegetable intake ${ }^{2}$. The World Health Organization has estimated that low fruit and vegetable intake is a cause of approximately 16.0 million disabilityadjusted lost years of life (1.0\% of the overall total) and 1.7 million deaths ( $2.8 \%$ of all deaths) worldwide each year ${ }^{3}$.

Fruit and vegetable intake can be increased via improved 
access to these foods. A systematic review ${ }^{4)}$ demonstrated the relationship between fruit and vegetable intake and certain environmental access factors, such as perceived accessibility of food stores or of these foods in the stores and having a vegetable garden or homegrown produce.

In regions with high fruit and vegetable production, easy access to these foods may contribute to more frequent consumption. For example, the family members of fruit and vegetable cultivators can enjoy fresh produce cultivated on their own property. In addition, the families that do not grow fruits and vegetables themselves can obtain them more conveniently if they have neighbors who do cultivate them, or if they can patronize a farmers' market nearby. Many reports have indicated a positive relationship between fruit and vegetable intake and cultivation of these foods ${ }^{5-12)}$ or utilization of farmers' markets ${ }^{12}$. There exists a similarly positive relationship between the intake of homegrown fruits and vegetables and the total intake ${ }^{13)}$. A study in Japan found a positive relationship between the received vegetable intake and the total vegetable intake ${ }^{14)}$. Further, an ecological study conducted in Japan determined a positive correlation between the mean vegetable intake and the amount of notfor-sale vegetables produced in each prefecture ${ }^{15)}$; however, it is uncertain whether the individual families' practice of cultivating vegetables or obtaining them from their neighbors is responsible for this positive correlation, because the analysis took place only at the prefectural level ${ }^{15)}$.

Accordingly, further research is needed to examine the differences in the fruit and vegetable intake among the regions and how participation in vegetable cultivation, obtaining vegetables from neighbors, and purchasing vegetables at farmers' markets can impact these differences. There is more intake $^{16)}$ and cultivation ${ }^{17,18)}$ of vegetables than of fruits in Japan, and yet the mean vegetable intake among the Japanese adults ${ }^{16)}$ remains below the nationally recommended leve ${ }^{19)}$. Therefore, research on vegetable intake is especially necessary.

This study aimed at identifying the differences in the vegetable intake frequency among the rural, suburban, and urban residents in a city in the Gunma prefecture, Japan. It also intended to estimate the effects of vegetable cultivation, receiving vegetables, and purchasing vegetables at farmers' markets on the differences in the vegetable intake. After reporting the results, we discuss the value of supporting vegetable cultivation in the rural areas in order to maintain vegetable intake levels.

\section{Materials and Methods}

\section{Study participants and design}

The participants in this cross-sectional study were resi- dents aged between 20 and 74 years, living in three parts of city A in the Gunma prefecture, Japan. A is located in the center of Gunma, covers $459.2 \mathrm{~km}^{2}$, and has a population of approximately 0.37 million residents. In order to conduct surveys in one city, there was no need to consider the influence of policies established by the local government. Within this city, we identified three geographic regions, each with a population of about 1,000 people aged between 20 and 74 years, which could be classified as rural, suburban, and urban, respectively. This is because, a power analysis calculation indicated that for an effect size of 0.1 and power of 0.7 , at least 774 (258 in each area) participants, and power of 0.8 , at least 967 (323 in each area) participants would be required. The response rate was assumed to be about $30 \%$. Rural area B is located to the northwest of city A, and vegetable cultivation flourishes there (607 households). Suburban area $\mathrm{C}$ is located in the middle of the city. Vegetable cultivation flourished there once, but now, the amount of agriculture has reduced due to land conversion for residential or commercial use (743 households). Urban area D, on the eastern side of city $\mathrm{A}$, is the most urbanized region in the city (910 households).

We collected survey data in September and October 2016 using a self-administered questionnaire. We mailed two sets of questionnaires to all households in the three areas on September 12, using TOWNPLUS by Japan Post Co., Ltd. This service helps send mails to all households in the selected areas, without even knowing the specific addresses. An explanatory letter and a stamped, self-addressed return envelope were enclosed with the questionnaire. The explanatory letter stated the following: (1) there is no need to reply if there are no residents aged between 20 and 74 years in the household; (2) two residents should reply if there are three or more residents aged between 20 and 74 years in the household; (3) the survey is anonymous, and we regard submitting a response to the questionnaire as consent. In addition, we numbered each questionnaire so that we could identify which of the three geographic areas each response came in from.

This study was approved by the Gunma University Ethical Review Board for Medical Research Involving Human Subjects (Submission No. 160074, approved August 16, 2016).

\section{Survey tool}

The survey requested information on vegetable intake frequency (number of times per day), self-perceptions of vegetable cultivation, frequency of receiving vegetables (i.e., obtaining them from neighbors), frequency of vegetable purchase at farmers' markets, subjective difficulty in food-store access, economic circumstances, health atti- 
tudes, and demographic characteristics (sex, age group, educational background, and employment status).

Vegetable intake frequency was assessed using four items based on the Behavioral Risk Factor Surveillance System (BRFSS) ${ }^{20}$. We carefully selected four appropriate items for evaluating the vegetable intake by Japanese people (vegetable juice; dark green vegetables; red, yellow, and orange vegetables; and other vegetables) because the BRFSS was originally prepared for the American context. In each vegetable category, the questionnaire asked, "How many times per day, on average, have you eaten the following vegetables in the past month?" Participants were provided with examples of the vegetables included in each of the four categories, but were not given a definition of the serving size. Based on these responses, we created an index of the vegetable intake (total number of times per day) by summing the intake data for all four items.

To understand the self-perceptions of vegetable cultivation, we asked the participants, "Do you or your household members grow vegetables?" Participants who answered yes were further asked whether they grew the vegetables as "a farmer," or as a "home gardener, community gardener, or other gardener." Based on these responses, we classified those who answered "farmer" as "vegetable cultivation as a farmer" and those who answered "home gardener, community gardener, or other gardener" as "vegetable cultivation as a non-farmer."

We also asked the participants, "During the past month, how often have you received vegetables?" and "During the past month, how often have you purchased vegetables at farmers' markets?" Participants answered on a scale from 0 (never) to 3 (often).

We assessed the subjective difficulty in food-store access by using a single item from a previous study which asked the participants about their general difficulty in food-store access on a scale from 0 (very difficult) to 3 (very easy) ${ }^{21)}$.

We assessed the economic circumstances using a single item, which asked the participants to indicate their economic situation on a scale of 1 (very poor) to 5 (very good). This item was confirmed as having a positive relationship with the household income in a study in the past ${ }^{22}$.

We assessed the health attitude using a single item: "Are you usually health-conscious?" Participants answered on a scale of 0 (not at all) to 3 (often or all the time).

As mentioned above, the demographic questions were asked for the respondents' gender, age group (years; 20-29 $=0,30-39=1,40-49=2,50-59=3,60-69=4,70-74=5$ ), educational background (elementary or junior high school $=$ 0 , high school $=1$, vocational school or junior college $=2$, university or graduate school $=3$ ), and employment status (unemployed or retired $=0$, part-time $=1$, full-time $=2$ ).

\section{Analysis}

We used the analysis of covariance (ANCOVA). Prior to the ANCOVA, we conducted two analyses. Initially, we analyzed the regional differences among all variables using one-way analysis of variance for interval scale, the Kruskal-Wallis test for ordinal scale, and the chi-square test for categorical scale. We conducted multiple comparisons using Tukey's honestly significant difference test for interval scale, and the Bonferroni correction for ordinal and categorical scales. We then conducted further analysis using a multiple regression model to confirm the relationships between vegetable intake frequency and all the other variables. Based on the results of these analyses, we determined the co-variables for the ANCOVA.

In the ANCOVA, we constructed a series of models, starting with a model adjusted for the demographic and health characteristics (Model 1) to assess whether any regional differences existed or did not exist. We then constructed models adjusted for vegetable cultivation, receiving vegetables, and vegetable purchase at farmers' markets, respectively (Models 2-4). These models assessed the single effect of each variable on the regional differences. Eventually, we developed a model including all variables used in Models 1-4 (Model 5) to assess the total effect of vegetable cultivation, receiving vegetables, and vegetable purchase at farmers' markets on the regional differences.

We conducted multiple comparisons with the Bonferroni correction for all models. If the regional differences reduced as a result of the adjustment, we could confirm the effect of vegetable cultivation, receiving vegetables, and/ or vegetable purchase at farmers' markets on the regional differences in the vegetable intake frequency. Additionally, we could determine the magnitude of the effect by comparing the estimated means for vegetable intake frequency. Sex (reference: women) and vegetable cultivation (reference: no cultivation) were used as dummy variables for the multiple regression model and ANCOVA. For other variables, it was confirmed that the absolute value of skewness and kurtosis was less than 2 , and hence, other variables were used as interval scale for the multiple regression model and ANCOVA. Statistical models were checked for the interactive effects between the geographic areas and all other variables included in the models, and were found to be acceptable. A two-tailed $p$-value less than 0.05 was considered as statistically significant. All analyses were performed using the IBM SPSS Statistics 23.

\section{Results}

We mailed questionnaires to 2,260 households and received responses from 586 households (household response 
rate: $25.9 \%$ ). A total of 873 residents responded: 295 from area B, 295 from area C, and 283 from area D. We excluded responses which had data missing (76), outliers (those who were above 74 (4), and people who claimed to eat vegetables more than 12 times per day (10)), leaving 783 responses $(257$ in area B, 259 in area C, 267 in area D) available for statistical analysis.

The results from the analysis of the regional differences among all variables showed significant differences in the age group $(p<0.001)$, educational background ( $p<$ $0.001)$, employment status $(p=0.014)$, subjective difficulty in food-store access $(p<0.001)$, economic circumstances $(p<0.001)$, vegetable cultivation as a farmer $(p<0.001)$, vegetable cultivation as a non-farmer $(p<0.001)$, frequency of receiving vegetables $(p<0.001)$, frequency of vegetable purchase at farmers' markets $(p<0.001)$, and vegetable intake frequency $(p<0.001)$ (Table 1$)$. The results of the multiple comparison showed that the population performing vegetable cultivation as farmers, the frequency of receiving vegetables, and the frequency of vegetable purchase at farmers' markets were all significantly higher in area B, than they were in areas C and D. Meanwhile, the population engaged in vegetable cultivation as non-farmers was significantly higher in both areas B and C, than in area D.

We then showed, using a multiple regression model (Table 2$)$, that sex $(p<0.001)$, age group $(p=0.001)$, economic circumstances $(p=0.006)$, health attitudes $(p<0.001)$, vegetable cultivation as a farmer $(p<0.001)$, vegetable cultivation as a non-farmer $(p=0.013)$, frequency of receiving vegetables $(p=0.004)$, and frequency of vegetable purchase at farmers' markets ( $p=0.037)$, all had significant relationships with the vegetable intake frequency. Age group, educational background, and employment status were significantly correlated with each other. Therefore, we used only age group as a demographic factor, since it was the most strongly correlated with vegetable intake frequency.

Results of the ANCOVA are listed in Table 3. Initially, we analyzed the regional differences of the vegetable intake frequency adjusted for age group and economic circumstances. These co-variables were seen both, as displaying significant regional differences, and as being related to vegetable intake frequency. As a result (Model 1), a significant regional difference in the vegetable intake frequency was seen $(F=20.3, p<0.001)$. Multiple comparisons revealed that the vegetable intake frequency by the residents of the rural area was higher than that of the residents in the urban and suburban areas. These trends also appeared in Models 2 to 4 . However, the differences tended to be smaller (Model 2: $F=11.0, p<0.001$; Model 3: $F=16.6, p<0.001$; Model 4: $F=18.5, p<0.001)$. The regional differences were the smallest in Model $5(F=8.1, p<0.001)$. No significant difference was observed between the rural and urban areas with regard to the vegetable intake frequency in Model 5. Alternatively, significant differences were still seen between the rural and suburban areas. As for the estimated means, the average vegetable intake frequency in the rural area in Model 1 was greater than that in the suburban area by 1.1 times and exceeded that in the urban area by 1.2 times. These differences reduced in Model 5: 0.8 times for the suburban area and 0.5 times for the urban area.

\section{Discussion}

Our study revealed that the vegetable intake frequency among the residents in the rural area was higher than that of the residents in the urban and suburban areas of a city in the Gunma prefecture, Japan. In addition, we found that these differences were partially due to the differences in vegetable cultivation, receiving vegetables, and vegetable purchase at farmers' markets.

Various studies have investigated the factors that influence vegetable intake. Past studies have identified these factors as health attitude ${ }^{23}$, perceived accessibility of food stores $^{4)}$, and household income ${ }^{24)}$. In our study, we asked the participants to respond to items on health attitude, economic circumstances, and subjective difficulty in food-store access. However, no regional difference was seen in the health attitude. Subjective difficulty in food-store access was not related to vegetable intake frequency in this study. Moreover, the regional differences in vegetable intake frequency were observed even when we adjusted for economic circumstances. Hence, we can conclude that the causes of these regional differences are factors other than health attitude, food-store access, and economic status.

The regional differences in the vegetable intake frequency reduced when we adjusted for vegetable cultivation, receiving vegetables, and vegetable purchase at farmers' markets. These results indicate that the regional differences in the vegetable intake frequency between the rural, suburban, and urban areas are partially based on these three factors. Several studies in the past have also noted the positive relationships between vegetable intake and these factors ${ }^{5-12,14)}$. Moreover, the frequency of receiving vegetables and that of vegetable purchase at farmers' markets were highest in area $\mathrm{B}$, which had the maximum number of farmers cultivating vegetables. In particular, the presence of farmers cultivating vegetables affects the vegetable intake of residents in a region, directly and indirectly.

Accordingly, it can be concluded that maintaining vegetable cultivation in the rural areas contributes to high frequency of vegetable intake of the rural residents. According to the results of this study, supporting agriculture is impor- 
Table 1 Regional differences among all variables

\begin{tabular}{|c|c|c|c|c|c|c|c|c|c|c|}
\hline & \multicolumn{2}{|c|}{$\begin{array}{c}\text { total } \\
(\mathrm{n}=783)\end{array}$} & \multicolumn{2}{|c|}{$\begin{array}{l}\text { B. rural } \\
(\mathrm{n}=257)\end{array}$} & \multicolumn{2}{|c|}{$\begin{array}{c}\text { C. suburban } \\
(\mathrm{n}=259)\end{array}$} & \multicolumn{2}{|c|}{$\begin{array}{l}\text { D. urban } \\
(\mathrm{n}=267)\end{array}$} & \multirow[t]{2}{*}{$p$} & \multirow{2}{*}{$\begin{array}{l}\text { Multiple } \\
\text { comparison }\end{array}$} \\
\hline & $\mathrm{n}$ & $\%$ & $\mathrm{n}$ & $\%$ & $\mathrm{n}$ & $\%$ & $\mathrm{n}$ & $\%$ & & \\
\hline \multicolumn{11}{|l|}{ Sex ${ }^{a}$} \\
\hline Men & 429 & 55 & 133 & 52 & 145 & 56 & 151 & 57 & 0.486 & \\
\hline Women & 354 & 45 & 124 & 48 & 114 & 44 & 116 & 43 & & \\
\hline \multicolumn{11}{|l|}{ Age group ${ }^{b}$} \\
\hline 20-29 & 25 & 3 & 8 & 3 & 8 & 3 & 9 & 3 & $<0.001$ & $B>C>D$ \\
\hline $30-39$ & 91 & 12 & 14 & 5 & 35 & 14 & 42 & 16 & & \\
\hline $40-49$ & 180 & 23 & 28 & 11 & 59 & 23 & 93 & 35 & & \\
\hline $50-59$ & 172 & 22 & 58 & 23 & 50 & 19 & 64 & 24 & & \\
\hline $60-69$ & 228 & 29 & 119 & 46 & 75 & 29 & 34 & 13 & & \\
\hline $70-74$ & 87 & 11 & 30 & 12 & 32 & 12 & 25 & 9 & & \\
\hline \multicolumn{11}{|l|}{ Educational background ${ }^{\mathrm{b}}$} \\
\hline Elementary or junior high school & 50 & 6 & 36 & 14 & 14 & 5 & 0 & 0 & $<0.001$ & $\mathrm{D}>\mathrm{C}>\mathrm{B}$ \\
\hline High school & 296 & 38 & 133 & 52 & 109 & 42 & 54 & 20 & & \\
\hline Vocational school or junior college & 208 & 27 & 59 & 23 & 72 & 28 & 77 & 29 & & \\
\hline University or graduate school & 229 & 29 & 29 & 11 & 64 & 25 & 136 & 51 & & \\
\hline \multicolumn{11}{|l|}{ Employment status ${ }^{\mathrm{b}}$} \\
\hline Unemployed or retired & 254 & 32 & 88 & 34 & 91 & 35 & 75 & 28 & 0.014 & $\mathrm{D}>\mathrm{B}$ \\
\hline Part-timer & 128 & 16 & 54 & 21 & 40 & 15 & 34 & 13 & & \\
\hline Full-time worker & 401 & 51 & 115 & 45 & 128 & 49 & 158 & 59 & & \\
\hline \multicolumn{11}{|l|}{ Subjective difficulty in food-store access ${ }^{b}$} \\
\hline Very difficult & 19 & 2 & 9 & 4 & 4 & 2 & 6 & 2 & $<0.001$ & $\mathrm{DC}>\mathrm{B}$ \\
\hline Difficult & 198 & 25 & 90 & 35 & 46 & 18 & 62 & 23 & & \\
\hline Easy & 372 & 48 & 123 & 48 & 130 & 50 & 119 & 45 & & \\
\hline Very easy & 194 & 25 & 35 & 14 & 79 & 31 & 80 & 30 & & \\
\hline \multicolumn{11}{|l|}{ Economic circumstance $^{\mathrm{b}}$} \\
\hline Very poor & 28 & 4 & 7 & 3 & 15 & 6 & 6 & 2 & $<0.001$ & $\mathrm{D}>\mathrm{CB}$ \\
\hline Poor & 152 & 19 & 58 & 23 & 64 & 25 & 30 & 11 & & \\
\hline Fair & 278 & 36 & 100 & 39 & 93 & 36 & 85 & 32 & & \\
\hline Good & 237 & 30 & 77 & 30 & 72 & 28 & 88 & 33 & & \\
\hline Very good & 88 & 11 & 15 & 6 & 15 & 6 & 58 & 22 & & \\
\hline \multicolumn{11}{|l|}{ Health attitude ${ }^{b}$} \\
\hline Not at all & 30 & 4 & 10 & 4 & 10 & 4 & 10 & 4 & 0.291 & \\
\hline Little & 202 & 26 & 69 & 27 & 71 & 27 & 62 & 23 & & \\
\hline Occasionally & 356 & 45 & 111 & 43 & 123 & 47 & 122 & 46 & & \\
\hline Often all the time & 195 & 25 & 67 & 26 & 55 & 21 & 73 & 27 & & \\
\hline \multicolumn{11}{|l|}{ Vegetable cultivation as a farmer ${ }^{\text {a }}$} \\
\hline Yes & 105 & 13 & 76 & 30 & 26 & 10 & 3 & 1 & $<0.001$ & $\mathrm{~B}>\mathrm{C}>\mathrm{D}$ \\
\hline No & 678 & 87 & 181 & 70 & 233 & 90 & 264 & 99 & & \\
\hline \multicolumn{11}{|l|}{ Vegetable cultivation as a nonfarmer ${ }^{\text {a }}$} \\
\hline Yes & 284 & 36 & 118 & 46 & 122 & 47 & 44 & 16 & $<0.001$ & $\mathrm{BC}>\mathrm{D}$ \\
\hline No & 499 & 64 & 139 & 54 & 137 & 53 & 223 & 84 & & \\
\hline \multicolumn{11}{|l|}{ Frequency of receiving vegetables ${ }^{b}$} \\
\hline Never & 162 & 21 & 33 & 13 & 48 & 19 & 81 & 30 & $<0.001$ & $\mathrm{~B}>\mathrm{CD}$ \\
\hline Rarely & 227 & 29 & 71 & 28 & 82 & 32 & 74 & 28 & & \\
\hline Sometimes & 254 & 32 & 91 & 35 & 89 & 34 & 74 & 28 & & \\
\hline Often & 140 & 18 & 62 & 24 & 40 & 15 & 38 & 14 & & \\
\hline Frequency of vegetable purchase at farm & & & & & & & & & & \\
\hline Never & 377 & 48 & 106 & 41 & 124 & 48 & 147 & 55 & $<0.001$ & $\mathrm{~B}>\mathrm{CD}$ \\
\hline Rarely & 141 & 18 & 42 & 16 & 53 & 20 & 46 & 17 & & \\
\hline Sometimes & 206 & 26 & 76 & 30 & 69 & 27 & 61 & 23 & & \\
\hline Often & 59 & 8 & 33 & 13 & 13 & 5 & 13 & 5 & & \\
\hline & Mean & SE & Mean & SE & Mean & SE & Mean & SE & & \\
\hline$V$ egetable intake frequency (times/day) ${ }^{c}$ & 4.9 & 0.1 & 5.8 & 0.2 & 4.5 & 0.1 & 4.6 & 0.1 & $<0.001$ & $\mathrm{~B}>\mathrm{C}>\mathrm{D}$ \\
\hline
\end{tabular}

${ }^{\mathrm{a}}: \chi^{2}$ test, ${ }^{\mathrm{b}}:$ Kruskal-Wallis test, ${ }^{\mathrm{c}}:$ one-way ANOVA. SE: standard error. 
Table 2 Correlation coefficients and results of multiple regression model: Relationship between vegetable intake frequency and all other variables

\begin{tabular}{lrr}
\hline & \multicolumn{2}{c}{ Vegetable intake frequency } \\
\cline { 2 - 3 } & \multicolumn{1}{c}{$r$} & \multicolumn{1}{c}{$\beta$} \\
\hline Sex (Ref: women) & $-0.129 * *$ & $-0.114 * *$ \\
Age group & $0.214 * *$ & $0.120 * *$ \\
Educational background & $-0.150 * *$ & \\
Employment status & $-0.180 * *$ & \\
Subjective difficulty in food-store access & $<0.001$ & \\
Economic circumstance & $0.139 * *$ & $0.092 * *$ \\
Health attitude & $0.275 * *$ & $0.197 * *$ \\
Vegetable cultivation as a farmer & $0.172 * *$ & $0.194 * *$ \\
Vegetable cultivation as a nonfarmer & $0.103 * *$ & $0.090 *$ \\
Frequency of receiving vegetable & $0.099 * *$ & $0.098 * *$ \\
Frequency of vegetable purchase at farmers' markets & $0.174 * *$ & $0.074 *$ \\
\hline
\end{tabular}

$\mathrm{R}^{2} / \mathrm{AR}^{2}=0.17 / 0.16 . \mathrm{n}=783 . r=$ Correlation coefficients, $\beta=$ Standard partial regression coefficients. $* p<0.05, * * p<0.01$.

Table 3 Results of ANCOVA (vegetable intake frequency (times/day))

\begin{tabular}{|c|c|c|c|c|c|c|c|c|c|c|}
\hline & \multicolumn{2}{|c|}{ B. rural } & \multicolumn{2}{|c|}{ C. suburban } & \multicolumn{2}{|c|}{ D. urban } & \multirow{2}{*}{\multicolumn{2}{|c|}{$\begin{array}{c}\text { Differences of } \\
\text { Means }\end{array}$}} & \multirow{3}{*}{$\begin{array}{l}F \\
p\end{array}$} & \multirow{3}{*}{$\begin{array}{c}\text { Multiple } \\
\text { comparison }\end{array}$} \\
\hline & Mean & SE & Mean & SE & Mean & $\mathrm{SE}$ & & & & \\
\hline & \multicolumn{2}{|c|}{$(95 \% \mathrm{CI})$} & \multicolumn{2}{|c|}{$(95 \% \mathrm{CI})$} & \multicolumn{2}{|c|}{$(95 \% \mathrm{CI})$} & $\mathrm{B}-\mathrm{C}$ & B-D & & \\
\hline \multirow[t]{2}{*}{ Model 1} & 5.7 & 0.1 & 4.6 & 0.1 & 4.5 & 0.1 & 1.1 & 1.2 & 20.3 & $\mathrm{~B}>\mathrm{CD}$ \\
\hline & \multicolumn{2}{|c|}{$(5.4-6.0)$} & \multicolumn{2}{|c|}{$(4.3-4.8)$} & \multicolumn{2}{|c|}{$(4.3-4.8)$} & & & $<0.001$ & \\
\hline \multirow[t]{2}{*}{ Model 2} & 5.5 & 0.2 & 4.5 & 0.1 & 4.8 & 0.2 & 1.0 & 0.7 & 11.0 & $\mathrm{~B}>\mathrm{CD}$ \\
\hline & \multicolumn{2}{|c|}{$(5.2-5.8)$} & \multicolumn{2}{|c|}{$(4.3-4.8)$} & \multicolumn{2}{|c|}{$(4.5-5.1)$} & & & $<0.001$ & \\
\hline \multirow[t]{2}{*}{ Model 3} & 5.6 & 0.1 & 4.6 & 0.1 & 4.6 & 0.1 & 1.0 & 1.0 & 16.6 & $\mathrm{~B}>\mathrm{CD}$ \\
\hline & \multicolumn{2}{|c|}{$(5.3-5.9)$} & \multicolumn{2}{|c|}{$(4.3-4.8)$} & \multicolumn{2}{|c|}{$(4.3-4.9)$} & & & $<0.001$ & \\
\hline \multirow[t]{2}{*}{ Model 4} & 5.7 & 0.1 & 4.6 & 0.1 & 4.6 & 0.1 & 1.1 & 1.1 & 18.5 & $\mathrm{~B}>\mathrm{CD}$ \\
\hline & \multicolumn{2}{|c|}{$(5.4-5.9)$} & \multicolumn{2}{|c|}{$(4.3-4.9)$} & \multicolumn{2}{|c|}{$(4.3-4.9)$} & & & $<0.001$ & \\
\hline \multirow[t]{2}{*}{ Model 5} & 5.4 & 0.2 & 4.6 & 0.1 & 4.9 & 0.2 & 0.8 & 0.5 & 8.1 & $\mathrm{~B}>\mathrm{C}$ \\
\hline & \multicolumn{2}{|c|}{$(5.1-5.7)$} & \multicolumn{2}{|c|}{$(4.3-4.8)$} & \multicolumn{2}{|c|}{$(4.5-5.2)$} & & & $<0.001$ & \\
\hline
\end{tabular}

$\mathrm{N}=783$, B. rural: $\mathrm{n}=257$, C. suburban: $\mathrm{n}=259$, D. urban: $\mathrm{n}=267$; Mean: estimated mean; SE: standard error. Covariables of Model 1: age group, economic circumstance, Model 2: age group, economic circumstance, vegetable cultivation as a farmer, vegetable cultivation as a non-farmer, Model 3: age group, economic circumstance, frequency of receiving vegetable, Model 4: age group, economic circumstance, frequency of vegetable purchase at farmers' markets, Model 5: all co-variables of Models 1 through 4.

tant, not only for the economic sustenance of the rural residents, but also to maintain their high frequency of vegetable intake. This discovery enhances the significance of supporting agriculture in rural areas, as doing so can contribute to the health as well as economic welfare of the residents. Agriculture can be supported not only through public support but also through support by community members. Community-supported agriculture ${ }^{25)}$ is one way to support agriculture by community members. Moreover, it is not practical to widely promote vegetable cultivation in urban areas; however, community gardens have been established even in urban areas, and participation in community gardens has been found to be positively related to vegetable intake ${ }^{6-8,10,12)}$. Therefore, it may also be important to consider promoting the establishment of places for vegetable cultivation, such as community gardens in urban areas.

Nevertheless, since the differences between regions remained after we adjusted for vegetable cultivation, receiving vegetables, and vegetable purchase at farmers' markets, the regional differences found in this study are not solely attributable to these factors. We presume that psychological factors, such as belief in the safety of locally grown produce and stronger preference for vegetables, could also play a considerable role. For example, the positive relationship be- 
tween local food consumption and preference of safety vegetables in Japan has been confirmed ${ }^{26)}$. In addition, among high school students, having home gardens or prior experience with community gardens or farms have been positively related with local food perceptions ${ }^{27}$. In area $\mathrm{B}$, there are probably several residents who like vegetables and consume locally grown vegetables regularly as safety vegetables, given the still-flourishing vegetable production in this area. Moreover, it has been confirmed that "cheap" is an important component of motivation to use farmers' markets ${ }^{28}$. Regardless of the economic status, the recognition of the fact that it facilitates saving money is presumed to be a motivation to consume locally grown vegetables. Furthermore, the recognition of low burden on the environment is also a factor that promotes the consumption of locally grown vegetables $^{29}$. However, these psychological factors were not considered in the present study and should be examined in future research.

This study has four limitations. First, the generalizability is limited, because we recruited participants from only three parts of one city by non-randomized sampling. Second, the validity of the responses regarding the vegetable intake frequency was not verified. Hence, we cannot assume with certainty that the responses accurately represent people's actual amount of vegetable intake. Third, a response bias may have been present, since the household response rate was $25.9 \%$. Fourth, as this was a cross-sectional study, we cannot make any inferences regarding causality. It is not practical to use a randomized controlled trial while considering the relationship between the regional vegetable production and intake. It is difficult to implement interventions designed to increase the amount of vegetable production in a region and then evaluate whether the intervention affects the vegetable consumption practices or not. Presumably, a natural experiment ${ }^{30)}$ may be a promising research strategy in order to reveal the causal relationships.

\section{Conclusion}

This study revealed the regional differences in the vegetable intake frequency, which was higher in the rural area than in the suburban or urban areas. In addition, a portion of these differences was attributable to the factors of vegetable cultivation, receiving vegetables, and vegetable purchase at farmers' markets. The frequency of receiving vegetables and of vegetable purchase at farmers' markets was higher in the rural areas where more people undertake vegetable cultivation as farmers. These results suggest that maintaining vegetable cultivation in rural areas contributes to the high frequency of vegetable intake of rural residents, both, directly and indirectly. Therefore, we should reconsider the value of supporting agriculture in rural areas, including the health of the local residents by promoting vegetable intake.

Conflict of Interest: The authors have no conflict of interest to report.

\section{Acknowledgments}

We would like to thank the participants in this study. This study was funded by the Nakatani Suzuyo Memorial Fund for Nutrition and Dietetics.

\section{References}

1. Boeing H, Bechthold A, Bub A, et al. Critical review: vegetables and fruit in the prevention of chronic diseases. Eur J Nutr 2012; 51: 637-663. [Medline] [CrossRef]

2. Wang X, Ouyang Y, Liu J, et al. Fruit and vegetable intake and mortality from all causes, cardiovascular disease, and cancer:systematic review and dose-response meta-analysis of prospective cohort studies. BMJ 2014; 29: 349.

3. World Health Organization. Promoting fruit and vegetable intake around the world. http://www.who.int/dietphysicalactivity/fruit/en/ (accessed 12 September 2017).

4. Kamphuis CB, Giskes K, de Bruijn GJ, et al. Environmental determinants of fruit and vegetable consumption among adults: a systematic review. Br J Nutr 2006; 96: 620-635. [Medline]

5. Sommerfeld AJ, McFarland AL, Waliczek TM, et al. Growing minds: evaluating the relationship between gardening and fruit and vegetable intake in older adults. Horttechnology 2010; 20: 711-717.

6. Alaimo K, Packnett E, Miles RA, et al. Fruit and vegetable intake among urban community gardeners. J Nutr Educ Behav 2008; 40: 94-101. [Medline] [CrossRef]

7. Blair D, Giesecke CC, Sherman S. A dietary, social and economic evaluation of the Philadelphia urban gardening project. J Nutr Educ 1991; 23: 161-167. [CrossRef]

8. Barnidge EK, Hipp PR, Estlund A, et al. Association between community garden participation and fruit and vegetable consumption in rural Missouri. Int J Behav Nutr Phys Act 2013; 10: 128-135. [Medline] [CrossRef]

9. Carney PA, Hamada JL, Rdesinski R, et al. Impact of a community gardening project on vegetable intake, food security and family relationships: a community-based participatory research study. J Community Health 2012; 37: 874-881. [Medline] [CrossRef]

10. Litt JS, Soobader MJ, Turbin MS, et al. The influence of social involvement, neighborhood aesthetics, and community garden participation on fruit and vegetable consumption. Am J Public Health 2011; 101: 1466-1473. [Medline] [CrossRef]

11. Devine CM, Wolfe WS, Frongillo EA Jr, et al. Life-course events and experiences: association with fruit and vegetable consumption in 3 ethnic groups. J Am Diet Assoc 1999; 99: 
309-314. [Medline] [CrossRef]

12. McCormack LA, Laska MN, Larson NI, et al. Review of the nutritional implications of farmers markets and community gardens: a call for evaluation and research efforts. J Am Diet Assoc 2010; 110: 399-408. [Medline] [CrossRef]

13. Nanney MS, Johnson S, Elliott M, et al. Frequency of eating homegrown produce is associated with higher intake among parents and their preschool-aged children in rural Missouri. J Am Diet Assoc 2007; 107: 577-584. [Medline] [CrossRef]

14. Umezawa A, Miwa T, Shibui E, et al. Total Vegetable Intake and Homegrown Vegetable Intake in the Rural Area Residents of Hokkaido. Eiyogaku Zassi 2012; 70: 283-293 (Jpn J Nutr Diet). [CrossRef]

15. Machida D, Kushida O, Yoshida T. Relationship between vegetable intake and vegetable cultivation by prefecture in Japan: An ecological study at the prefectural level. Nihon Kenkoukyouiku Gakkaishi 2017; 25: 85-92 (JJHEP).

16. Ministry of Health Labor and Welfare. National Health and Nutrition Examination Survey 2016. http:/www.mhlw.go.jp/ bunya/kenkou/eiyou/dl/h27-houkoku-03.pdf. (accessed 12 September 2017, in Japanese).

17. Ministry of Agriculture Forestry and Fisheries. Crop survey (Vegetables). http://www.maff.go.jp/j/tokei/kouhyou/sakumotu/sakkyou_yasai/ (accessed 12 September 2017, in Japanese).

18. Ministry of Agriculture Forestry and Fisheries. Crop survey (Fruits). http://www.maff.go.jp/j/tokei/kouhyou/sakumotu/ sakkyou_kazyu/index.html (accessed 12 September 2017, in Japanese).

19. Ministry of Health Labor and Welfare. A Basic Direction for Comprehensive Implementation of National Health Promotion. http://www.mhlw.go.jp/file/06-Seisakujouhou10900000-Kenkoukyoku/0000047330.pdf (accessed 12 September 2017).

20. Centers of Disease Control and Prevention (2013). Behavioral Risk Factor Surveillance System Questionnaire. http://www. cdc.gov/brfss/questionnaires/pdf-ques/2013-brfss_english. pdf. (accessed 12 September 2017).

21. Yoshiba K, Takemi Y, Ishikawa M, et al. Relationship between dietary diversity and food access among elderly living alone in Saitama Prefecture. Nippon Koshu Eisei Zasshi 2015; 62: 707-718 (in Japanese, Abstract in English). [Medline]

22. Hayashi F, Takemi Y, Murayama N. The association between economic status and diet-related attitudes and behaviors, as well as diet-related quality of life in adults. Eiyogaku zassi (Jpn J Nutr Diet) 2015; 73: 51-61 (in Japanese, Abstract in English).

23. Aggarwal A, Monsivais P, Cook AJ, et al. Positive attitude toward healthy eating predicts higher diet quality at all cost levels of supermarkets. J Acad Nutr Diet 2014; 114: 266-272. [Medline] [CrossRef]

24. Darmon N, Drewnowski A. Does social class predict diet quality? Am J Clin Nutr 2008; 87: 1107-1117. [Medline] [CrossRef]

25. Vasquez A, Sherwood NE, Larson N, et al. Community-supported agriculture as a dietary and health improvement strategy: A narrative review. J Acad Nutr Diet 2017; 117: 83-94. [Medline] [CrossRef]

26. Oba R, Hirano T, Kurihara S. Graphical causal structure analysis of consumers' preference to local foods. Nouson Keikaku Gakkaisi 2006; 25: 413-418 (Journal of Rural Planning Association).

27. Greer AE, Davis S, Sandolo C, et al. Agricultural experiences are positively associated with high school students fruit and vegetable perceptions and consumption. J Nutr Educ Behav 2018; 50: 133-140.e1. [Medline] [CrossRef]

28. Tey YS, Arsil P, Brindal M, et al. Motivations underlying consumers' preference for farmers markets in Klang Valley: A means-end chain approach. Sustainability 2017; 9: 1958. [CrossRef]

29. Menapace L, Raffaelli R. Preferences for locally grown products: Evidence from a natural field experiment. ERAE 2017; 44: $255-284$

30. Barlow P, McKee M, Basu S, et al. Impact of the North American Free Trade Agreement on high-fructose corn syrup supply in Canada: a natural experiment using synthetic control methods. CMAJ 2017; 189: E881-E887. [Medline] [CrossRef] 